\title{
Breast and Cervical Cancer Screening Practices for Low-Income Asian American Women in Ethnic-Specific Clinics
}

\author{
Marjorie Kagawa-Singer ${ }^{1}$, Liane Wong ${ }^{2}$, Sara Shostak ${ }^{3}$, Chantal Raymer Walsh ${ }^{4}$, and Rod Lew ${ }^{5}$ \\ ${ }^{1}$ UCLA School of Public Health and Asian American Studies \\ ${ }^{2}$ Institute for Health Policy Solutions \\ ${ }^{3}$ Columbia University \\ ${ }^{4}$ Alta Bates Summit Medical Center \\ ${ }^{5}$ Asian Pacific Partners for Empowerment and Leadership
}

\begin{abstract}
Introduction: Early detection and screening are the most effective means to reduce cancer mortality in all populations. Asian American (AA) women have among the lowest rates in aggregate for use of early detection, and screening practices of all ethnic populations. The only nationally disaggregated populationbased data on these ethnic groups at the time of the study was the 1993-1994 National Health Interview Survey (NHIS) of English speaking AA, but $70 \%$ of the AA population is non-English speaking. Our study presents heretofore unavailable data for cancer screening for monolingual AA women for a comparable time period in California between 1992 and 1994, prior to initiation of the state and Federal programs targeting this group of women. Methods: Retrospective chart reviews of randomly selected medical records were conducted for the breast and cervical cancer screening practices of low-income, non-English speaking Chinese, Korean, and Thai women attending ethnic specific community-based health clinics. All women seen in the clinics between 1992-1994 who were within the appropriate screening age categories were eligible. Results: Asian American women utilizing ethnic specific clinics had equal to or better screening rates for mammography and Pap tests than mainstream services for English-speaking AA women in a national survey. These screening rates, however, were still well below nationally recommended screening rates for breast and cervical cancer according to Healthy People 2000 or 2010 goals. Conclusion: These data support the effectiveness of Community Based Clinics (CBOs) to reach these hard to reach women and address the call for the elimination of health disparities. In addition, we compare our findings with national data to highlight within group variations.
\end{abstract}

(C)2005 Californian Journal of Health Promotion. All rights reserved.

Keywords: screening, breast cancer, cervical cancer, Asian American women

\section{Introduction}

Despite Federal promotion of breast screening programs that began in the early 1990s through the Center for Disease Control and Health Promotion (CDCHP), Breast and Cervical Cancer Program (BCCCP), and simultaneously in California with the Breast Cancer Early Detection Program (BCEDP) to reach uninsured women, screening rates for Asian American women have consistently been lower than almost all other ethnic groups (Chen, 2004), while between 1988 and 1992 they had the fastest increase of cancer mortality among all ethnicities (Miller, Bernstein, Young, Swanson,
West, Key et al., 1996). The mortality rate of AA women has not decreased (Kwong, 2004). The objective set in Healthy People 2000 for breast health was to achieve an $80 \%$ rate of mammography screening for women over 50 years of age. For cervical cancer screening, the goal was for $90 \%$ of U.S. women over 18 years of age to be screened within the last two years. While non-Hispanic white women were very close to achieving these goals in 2000 , at $76 \%$ for both mammography and cervical screening, screening practices for breast and cervical cancer were underused by women of all minority 
ethnic groups (Kagawa-Singer \& Maxwell, 1998).

Most studies indicate that Asian American and Pacific Islander (AA) women, in aggregate, have among the lowest breast and cervical cancer screening rates of all ethnic populations $(41 \%$ and 65\%) (American Cancer Society, 2005; Kagawa-Singer \& Maxwell, 1998; (Parker, Davis, Wingo, Ries, \& Heath, 1998). Screening rates for a disaggregated sample of Asian American women from the 1994-1995 National Health Interview Survey (NHIS) showed the lowest screening rates of all ethnic populations. Notably though, data from the national surveys are used to determine policy and programmatic priorities, the NHIS does not reflect representative samples of Asian American populations. For example, the NHIS survey is only administered in English and over a third of the Asian American population does not speak English (U.S. Census Bureau, 2000). Therefore, our study sought to determine the breast and cervical cancer screening rates for Asian American women not represented in any of the national databases, that is primarily low-income, monolingual Asian American women, who used community based ethnic specific health clinics for their care in the same time period as the NHIS data was collected as a comparison of within group variation (Kagawa-Singer \& Pourat, 2000).

Office of Management and Budget (OMB) Directive 15 defines Asian Americans as anyone with "origins in any of the original peoples of the Far East, Southeast Asia, the Indian subcontinent, or the Pacific Islands" (OMB, 1997). The Asian American and Pacific Islander umbrella category is enormously heterogeneous comprised of 57 nationalities with over 100 languages spoken (Lai \& Arguelles, 2003). However, this diversity is not reflected in the major surveys for cancer screening, incidence, or mortality. For example, the National Cancer Institute Surveillance, Epidemiology and End Results (SEER) data base for cancer incidence in 2000 collected data for Asian Americans in only six subgroups: Chinese, Filipino, Hawaiian, Japanese, Korean and Vietnamese. The Behavioral Risk Factor Surveillance Survey
(BRFSS) conducted in each state, and in English (and Spanish) only, reports national data on Asian Americans only as a single aggregate group; subgroup information is not available at the national level. In California, which is home to almost $40 \%$ of the Asian American population of the U.S., BRFSS data has been collected for fourteen Asian American categories since 1996, but these subgroups are collapsed in the national BRFSS database into an aggregate Asian American category. Similar procedures occur in the CDC BCCCP Program as well. The National Health Interview Survey (NHIS) designates ten Asian American groups, however, because the survey is conducted only in English and Spanish, the sample does not represent the national Asian American population. Almost $72 \%$ of Asian Americans are foreign born, and of those, over $33 \%$ are monolingual in their native language (U.S. Census Bureau, 2000). For the NHIS, monolingual Asian Americans are asked to request the assistance of an English speaker in the household to complete the survey, but few participate (U.S. Census Bureau, 2000). The limitations of this national data have both clinical and programmatic implications, because even though national data reflects that Asian Americans have the lowest utilization rates for early detection services, such data does not represent the groups at higher risk for late stage presentation (low income, monolingual women) or reflect the magnitude of the true extent of need for such services in specific populations, who are at higher risk of low utilization.

\section{Cancer Incidence}

The SEER data indicate that breast cancer incidence and mortality are lower for Asian Americans than for their non-Hispanic white counterparts. These data, however, also indicate that breast cancer incidence rates, stage at diagnosis, and survival of Asian American women vary considerably by ethnic subgroup. From 1988-1992, breast cancer incidence rates varied more than three-fold among specific Asian American populations (rates given are per 100,000): Korean (23.3), Southeast Asian (31.8), and Chinese women (52.1) had significantly lower rates than Japanese (74.0) and Filipino women (73.8) (American, 1996) (Lin-Fu, 1993). Notably, since that time, Deapen and colleagues 
(2002) predicted that the rates for Japanese American women would likely surpass those of white American women in 2000, who had rates of $110 / 100,000$.

Similar patterns are also found for cervical cancer. The cervical cancer incidence rate for all Asian American women in aggregate is $11.6 / 100,000$ compared to $8.3 / 100,000$ for all races (ACS, 2000). This figure, however, obscures the tremendous variation among ethnic subgroups. Cervical cancer is the second most common cancer diagnosis for Southeast Asian women $(35.2 / 100,000)$ and first for Vietnamese women who have five times the rate for all ethnic groups $(48.0 / 100,000)$ compared to whites (7.5\%) (Small, 1997). Cervical cancer, however, is not one of the five most common cancer sites for Asian Indian (66\%), Filipino (19.8\%), Korean women (14.7\%), Chinese (8\%), or Japanese-American women (5.7\%) (Chen, 2004; Parker et al., 1998).

\section{Demographics}

The Asian American population is the fastest growing ethnic minority population in the United States, comprising about $4 \%$ of the national population and predicted to constitute nearly $11 \%$ by the Year 2050 (U.S. Census Bureau, 2000). National survey sampling strategies and ethnic designations for data collection, however, have not kept pace with the projected increase and changing demographics of this population (Lai and Arguelles, 2003).

Notably, Asian Americans are the only US ethnic population with a bimodal distribution of the major indicators for low cancer screening rates. Asian Americans are over-represented at the highest and lowest levels of socioeconomic status, education and age. For example, data from the 2000 Census indicate that the poverty rate for Asian Americans overall is 12.6\% compared to the national average of $11 \%$ and a poverty rate of whites of 9.1\% (Census, 2000). For Japanese Americans the poverty rate is $6.6 \%$, yet in contrast, over $66 \%$ of all Southeast Asian groups live below the poverty level. The average household income level for Asian Americans is \$59, 324 compared to $\$ 54,698$ for white Americans. However, these household income figures are deceiving. Per capita, Asian Americans actually make $\$ 0.71$ cents to each dollar made by white Americans since they have typically have more family members than the White Americans, and their disposable income is considerably less since many immigrant families send money home to family in their native countries (Lai \& Arguelles, 2003). Insurance coverage also is problematic, $20 \%$ of the Asian American population had no insurance compared to $15 \%$ of the total US population.

The bimodal distribution for education is stark. Asian Americans have over twice the percentage of women with less than four years of elementary school compared to other ethnic groups (6.7\% compared to $2.1 \%$ ). Yet $40.5 \%$ of Asian Americans have at least 4-year college degrees compared to $24.1 \%$ for whites (U.S. Census Bureau, 2000).

The median age for the US is 33.4 years as compared to 31.2 for the Asian American population. Again, however, the singular focus on this aggregate figure masks important ethnic distinctions. Among Southeast Asians Vietnamese have the highest median age of 25.2 years, and the Hmong have the lowest at 12.5 years. Moreover, the median age for foreignborn women is 15.8 years, and over $72 \%$ of Asian Americans in the US are foreign born. However, Asian Americans also have the largest proportion of elderly. Korean and Vietnamese elderly have the highest proportion of uninsured status and self-reports of poorer health status than any other ethnic group (Tanjasiri, Wallace, \& Shibata, 1995). Moreover, Asian Americans in California have the largest proportion of linguistically isolated elderly individuals at 51\% (Lai \& Arguelles, 2003). And again, the percentage of linguistically isolated elderly varies considerably by Asian American group: Hmong, 61\%, Kampuchean, 54.9\%, Laotian, $52 \%$, Vietnamese, 44\%, Korean 41\%, Chinese 40\%, Thai, 32\%, Japanese, 33\%, Filipino 13\%, and Samoan, 14.2\% (Kagawa-Singer, Hikoyeda, \& Tanjasiri, 1997). Thus a significant portion of older Asian American women do not practice screening due to low education, poverty and increased age without benefit of insurance. The linguistic and cultural barriers are significant, 
because older women are at increased risk for breast and cervical cancer.

\section{Screening Practices}

Due to the impressions left by most published data on Asian American cancer incidence, mortality, and early detection and screening practices indicate that Asian American women seem to have better overall health status, a significantly lower risk of cancer, and earlier stages of presentation of breast and cervical cancer than Hispanic or African American women. Therefore, Asian American women, as well as the general public, health practitioners, and policy makers, subscribe to the myth that Asian Americans are at low risk for breast and cervical cancer. As noted, however, the available data on the screening practices for Asian American are neither representative nor accurate. Kagawa-Singer and Maxwell conducted an extensive literature review and found only sixteen studies that report breast screening practices in Asian American groups (Kagawa-Singer \& Maxwell, 1998). All these studies were based on self-reported data. Some of these studies included monolingual Asian American women, but even these studies were conducted on local population based samples (McPhee SJ, 1997;Jenkins, Le, McPhee, Stewart, \& Ha, 1996);Taylor, Jackson, Schwartz,, Yutaka, Tu, Thompson, 1998; Maxwell, Bastani, \& Warda, 1998b; Wismer et al., 1998; Sadler et al., 2001; Taylor et al., 2002;)().

Disaggregated data on screening practices reveals a very troubling picture. Certain groups of Asian American women present later with more advanced disease than their white counterparts. Most notably, breast cancer in Asian American women also appears to occur at a younger age and in a more aggressive form than in white women (Menon, Teh, \& Chua, 1992).

According to the California BRFSS (1995), corresponding to the time period of this study, only $63 \%$ of Asian American women aged 50 and older reported ever having had a screening mammogram compared to $87 \%$ of white women. In the Northern California Chinese community and in Vietnamese communities throughout California (1989-1990) breast screening rates were also very low (Chen et al., 1992; Chen, Lew, Pham \& McPhee, 1992; Lee, Lee, \& Stewart, 1996; Lovejoy, Jenkins, Wu, Shankland, \& Wilson, 1989; Menon et al., 1992; Pham \& McPhee, 1992; Stephan J. McPhee et al., 1996; Thai et al., 1992). Over $68 \%$ of Chinese women and $48 \%$ of Vietnamese women reported never having received a mammogram compared to only $27 \%$ of white women. For clinical breast examinations, $47 \%$ of Vietnamese women aged forty and older reported never having the examination compared to only $11 \%$ of white women.

Similar disparities existed for cervical cancer as well. For example, Japanese-American, Vietnamese-, Filipino- and Korean-American women are all diagnosed with cervical cancer at later stages than white women, and Native Hawaiian and SEA women have the highest cervical cancer mortality rates of all ethnic groups. In the BRFSS, over $45 \%$ of Chinese women and 53\% of Vietnamese women reported that they had never had a Papanicolau test compared to only 6\% of white women (KagawaSinger \& Maxwell, 1998). California BRFSS data on cervical screening practices among other Asian American women is not available. Only one study has analyzed the screening rates for Asian American women from a nationally representative data base during the study period, and this as noted, also documented the lowest screening rates were in the Asian American populations (Kagawa-Singer \& Pourat, 2000).

Due to the lack of language accessibility and health insurance barriers, low income, nonEnglish speaking Asian American women are harder to reach and invisible in large surveys. The client population of ethnic specific community-based clinics is primarily comprised of these harder to reach Asian American women, and due to the bilingual-bicultural competency of the community based ethnic specific health clinics staff, we predicted that they would serve these populations successfully. 


\section{Methods}

\section{Sites}

California was selected for the study because, at the time, $40 \%$ of the Asian American population resided in California and also has the largest number of ethnic specific community based health centers serving this community -- 22 as of 2004 (U.S. Census Bureau, 2000). Five clinics were selected to participate in this study. All are members of the Association of Asian and Pacific Community Health Organizations (AAPCHO), a national coalition of 14 Asian American community health organizations. The clinics were informed of the study goals, purposes and methodology, and asked to participate as study sites. Overall, clinics were chosen to participate in this study based on their interest in participating, geographic and ethnic representation, and the availability and accessibility of medical records for the defined study period. Four ethnic groups comprised the study population: Chinese, Korean, Thai and Vietnamese. Two clinics were located in Northern California, and three clinics were located in Southern California.

The three-year period from January 1, 1992 to December 31, 1994 was chosen for review. This time period was selected to identify eligible women who might have received Pap testing and/or mammography at least two-year intervals (Healthy People 2000 Objectives). We also selected this time period to precede the effects that the federal Center for Disease Control Breast Cancer and Cervical Cancer Program (BCCCP) and the California State Breast Cancer Early Detection Program (BCEDP) would have in these communities, and also to correspond with the NHIS analysis of screening for Asian American women reported elsewhere (KagawaSinger \& Pourat, 2000). In this way, we would be able to provide the clinics with baseline information to gauge the impact of these two programs (BCCCP of the CDC and BCEDP of California) on their own inreach and outreach efforts and provide some data on the Asian American women not represented in the NHIS survey. The study research team was comprised of University researchers and Asian American specific community organization health educators and health care practitioners.

\section{Data Collection}

The data collection instrument was developed and pilot tested by the research team in four of the five sites to clarify response categories, medical record formats, and instrument length. The questionnaire was designed to provide data comparable to the NHIS questions. Data was collected retrospectively from medical chart reviews over a six-month period, from June 1, 1996 to January 31, 1997. The anonymous data was then sent to the central office of the AAPCHO for quality review and data entry into Microsoft Access. The data files and instruments were then sent to the University team for data cleaning, final coding of text entries, and data analysis.

\section{Sample}

Each clinic generated a list of all eligible women within each of the targeted ethnic groups at their clinic, who had utilized services at least twice within the study period (1994-1996). We anticipated obtaining a sample size of 200 women per ethnic group, but for reasons related to the timing of program implementation and the number of patients who had only one clinic visit over the review period, we were not able to obtain this optimal sample size. From the list of eligible women, researchers then generated a random selection of medical charts to review. Selection was based on the total number of eligible women at each site. In the clinics with larger samples, medical records were sequentially selected (e.g., every 5th or 10th record of eligible women). If the woman was found to be ineligible, a new chart was randomly selected from the remaining list of patients. In the case of one clinic, the entire ethnic population was sampled since their outreach program to the identified population was new and only covered the review period. Clinic staff trained specifically for this project conducted chart reviews.

Sample selection criteria for eligibility were: 1 ) women ages 40 and over in the four designated ethnic groups (born before January 1, 1952); 2) patients seen by a clinic practitioner at least twice during the three year designated review period for any health reason (to indicate inreach potential), and 3) patients who had no prior 
history of breast or cervical cancer prior to entering the clinic. If a patient had a diagnosis of breast cancer, the medical chart was reviewed for cervical cancer screening only. Likewise, if a patient had had a hysterectomy and no longer had a cervix, her chart was reviewed for breast health screening and breast self-examination instruction only. If a patient had both diagnoses of breast and cervical cancer, she was excluded from the study sample entirely, but no women fit these criteria. All data were coded by medical record number to protect patient confidentiality, and no personal identifying information was collected to protect patient anonymity. UCLA Institutional Review Board approval was obtained for this study.

\section{Results}

Due to the small numbers of Vietnamese women (33 and 9 "other"), and the fact that several studies have been published on the screening practices of this group including monolingual
Vietnamese (McPhee et al., 1996; Pham \& McPhee, 1992; Shinagawa et al., 1999). We restrict our analysis and discussion to the three larger groups in our sample of 627 women: Chinese (248), Korean (229) and Thai (117). The mean age for the total sample was 53.5, ranging from 40 to 85 years, with the Chinese being the oldest (mean age 55.7) and the Thai women the youngest (mean age 47.9). The majority of women (65\%) were married. A majority of the women were foreign born (ranging from $73.3 \%$ of the Chinese, $99.1 \%$ of Thai, $99.6 \%$ of Koreans, and $100 \%$ of the Vietnamese). The average time in the U.S. was 8.9 years, ranging from 9.1 for the Chinese to 4.5 for the Vietnamese. Only $7.9 \%$ reported that they were fluent in English (4.8\% to $15.2 \%$ ). More than two-thirds of the women were reported to be uninsured (81.5\%), and they had an average of 4.3 visits to the clinics (ranging from an average of 2.0 for the Thai women to 7.8 for the Chinese women).

Table 1

Sociodemographic Characteristics and Number of Clinic Visits for Women 40+ Years of Age, 1992-1994

\begin{tabular}{|l|c|c|c|}
\hline Sociodemographic Characteristics & No. & N & Percent \\
\hline Age (Mean number of years) & 53.5 & & \\
\hline Marital Status (\%) & & & \\
\hline Married & & & 64.8 \\
\hline Not Married & & & 35.2 \\
\hline Ethnicity & & & \\
\hline Chinese & & 248 & 39.6 \\
\hline Korean & & 117 & 36.5 \\
\hline Thai & & 33 & 18.7 \\
\hline Vietnamese & & & \\
\hline Country of Birth & & 184 & 28.6 \\
\hline China & & 14 & 2.2 \\
\hline Hong Kong & & 230 & 35.8 \\
\hline Korea & & 9 & 1.4 \\
\hline Philippines & & 7 & 1.1 \\
\hline Taiwan & & 116 & 18.0 \\
\hline Thailand & & 69 & 11.0 \\
\hline Vietnam & & 9 & 1.4 \\
\hline Other & 8.9 & & \\
\hline Number of Years in the US (Mean) & & & \\
\hline English Fluency & & & \\
\hline & & & \\
\hline
\end{tabular}




\begin{tabular}{|c|c|c|c|}
\hline Sociodemographic Characteristics & No. & N & Percent \\
\hline No & & 577 & 92.1 \\
\hline Insurance Status & & & \\
\hline Medi-Cal & & 74 & 11.5 \\
\hline Medicare & & 34 & 5.3 \\
\hline Private & & 11 & 1.7 \\
\hline Uninsured & & 515 & 81.5 \\
\hline Self-Pay & & 257 & 40.5 \\
\hline Missing* & 4.3 & & 40.0 \\
\hline Number of clinic visits (Mean) & & & \\
\hline * most likely uninsured
\end{tabular}

* most likely uninsured

Table 2

Breast Self-Examination, Clinical Breast Examination, Mammography and Pap Smear Screening Rates by Ethnicity, 1992-1994

\begin{tabular}{|l|c|c|c|c|}
\hline \multicolumn{1}{|c|}{ Clinical Test } & $\begin{array}{c}\text { Total Survey } \\
\text { Sample } \\
(\mathbf{N = 6 2 7 )}\end{array}$ & $\begin{array}{c}\text { Chinese } \\
\mathbf{( N = 2 4 8 )}\end{array}$ & $\begin{array}{c}\text { Korean } \\
\mathbf{( N = 2 2 9 )}\end{array}$ & $\begin{array}{c}\text { Thai } \\
\text { (N=117) }\end{array}$ \\
\hline Breast Self- Examination & $45 \%$ & $67 \%$ & $11 \%$ & $56 \%$ \\
\hline Clinical Breast Examination & $57 \%$ & $69 \%$ & $28 \%$ & $74 \%$ \\
\hline Mammography & $41 \%$ & $57 \%$ & $34 \%$ & $25 \%$ \\
\hline Pap Test & $65 \%$ & $71 \%$ & $52 \%$ & $74 \%$ \\
\hline
\end{tabular}

Over the three-year period, Chinese and Thai women were more than twice as likely (69\% and $70 \%$ respectively) as Korean women (30\%) to have had a clinical breast examination. However, these rates significantly decrease for the Chinese and Thai women for mammography screening. Only $24 \%$ of Thai women and $58 \%$ of Chinese women had had a mammogram. These rates fall far short of the goal of $80 \%$ for all women 50 years of age and older set forth in the Healthy People 2000 objectives. Rates for cervical cancer screening (Pap tests) were higher, although the rates for each group still fell below the Healthy People 2000 target of $90 \%$ of all women 18 years of age and older. Korean women had the lowest rates of screening at $52 \%$, then Thai women at $70 \%$ and Chinese women at $71 \%$.

Table 3 shows each of the screening practices by age and marital status. Both variables show significant effect on rates of screening. The lowest rates of screening were in single, older women.

Table 4 compares the rates of screening by the community-based agencies with the rates of screening practices for uninsured Asian women from the NHIS (Kagawa-Singer \& Pourat, 2000). Notably, the rates at community-based agencies are comparable for breast selfexaminations, lower for the clinical breast examination, and higher for mammograms and Pap tests. This would seem to indicate that the community-based clinics are effective in providing services to uninsured, monolingual Asian American women, who are identified as the most difficult to reach and least likely to receive these screening examinations. We are unable to assess the explanatory variables, but the rates were still below HP 2000 objectives and rates for white women at that time. 
Table 3

Breast Self-Examination, Clinical Breast Examination, Mammography and Pap Smear Rates by Age group and Marital Status, 1992-1994

\begin{tabular}{|c|c|c|c|}
\hline & $\begin{array}{c}\text { Chinese }(\mathrm{N}=248) \\
\%(\mathrm{~N})\end{array}$ & $\begin{array}{c}\text { Korean }(\mathrm{N}=229) \\
\%(\mathrm{~N})\end{array}$ & $\begin{array}{c}\text { Thai }(\mathrm{N}=117) \\
\%(\mathrm{~N})\end{array}$ \\
\hline Does Breast Self-Examination & $\mathrm{N}=166$ & $\mathrm{~N}=26$ & $\mathrm{~N}=66$ \\
\hline$<49$ years & $44.6(74)$ & $33.8(8)$ & $74.2(49)$ \\
\hline$>50$ years & $55.4(92)$ & $69.2(18)$ & $25.8(17)$ \\
\hline Not Married & $22.3(37)$ & $23.1(6)$ & $59.0(39)$ \\
\hline Married & $77.7(129)$ & $76.9(20)$ & $41.0(27)$ \\
\hline Had Clinical Breast Examination & $\mathrm{N}=181$ & $\mathrm{~N}=65$ & $\mathrm{~N}=87$ \\
\hline$<49$ years & $42.0(76)$ & $29.2(19)$ & $69.0(60)$ \\
\hline$>50$ years & $58.0(105)$ & $70.8(46)$ & $31.0(27)$ \\
\hline Not Married & $22.3(41)$ & $33.8(22)$ & $60.9(53)$ \\
\hline Married & $77.3(140)$ & $66.2(43)$ & $39.1(34)$ \\
\hline Had Mammogram & $\mathrm{N}=141$ & $\mathrm{~N}=77$ & $\mathrm{~N}=29$ \\
\hline$<49$ years & $39.0(55)$ & $31.2(24)$ & $72.4(21)$ \\
\hline$>50$ years & $61.0(86)$ & $69.8(53)$ & $27.6(8)$ \\
\hline Not Married & $29.8(42)$ & $28.6(22)$ & $58.6(17)$ \\
\hline Married & $70.2(99)$ & $71.4(55)$ & $41.4(12)$ \\
\hline Had Pap Test & $\mathrm{N}=176$ & $\mathrm{~N}=119$ & $\mathrm{~N}=87$ \\
\hline$<49$ years & $43.2(76)$ & $37.8(45)$ & $70.0(61)$ \\
\hline$>50$ years & $56.8(100)$ & $62.2(74)$ & $30.0(26)$ \\
\hline Not Married & $23.9(42)$ & 32.8 (39) & $40.2(35)$ \\
\hline Married & 76.1 (133) & $67.2(80)$ & $59.8(52)$ \\
\hline
\end{tabular}

Table 4

Breast Self-Examination, Clinical Breast Examination, Mammography and Pap Smear Screening Rates

\begin{tabular}{|l|c|c|}
\hline & $\begin{array}{c}\text { Total Survey Sample (N=627) } \\
\text { \% (N) }\end{array}$ & $\begin{array}{c}\text { NHIS* } \\
\text { (N=2756) }\end{array}$ \\
\hline Breast Self-Examination & $282(45 \%)$ & $45 \%$ \\
\hline Clinical Breast Examination & $357(57 \%)$ & $76 \%$ \\
\hline Mammography & $257(41 \%)$ & $25 \%$ \\
\hline Pap Test & $408(65 \%)$ & $54 \%$ \\
\hline
\end{tabular}

* NHIS 1994 and 1995. Kagawa-Singer and Pourat (2000).

\section{Discussion}

A comparison of these Asian American ethnic specific clinic screening rates of low-income, uninsured, monolingual AA women with those English speaking AA women from the 19931994 NHIS show surprisingly similar results, suggesting that these ethnic specific clinics make an important contribution to improving screening rates among clientele. For example, while $58 \%$ of Chinese women in the NHIS reported having received a mammogram, $59 \%$ of monolingual Chinese women in this study had received a mammogram. Similarly, $71 \%$ of Chinese women in the BRFSS reported having 
received a Pap test, and $71 \%$ of Chinese women in this sample had had the test.

The results from this current study indicate that $34 \%$ Korean women had gotten a mammogram, $29 \%$ had gotten a clinical breast examination (CBE), 12\% practiced breast self examination (BSE), and 52\% had gotten a Pap test. Two studies with English-speaking and monolingual Korean women over the age of 50 in northern California found that $34 \%$ had had mammograms, but $69 \%$ had a CBE in the previous 2 years and $24.2 \%$ had done a BSE monthly or more often (Wismer et al., 1996; Wismer et al., 1998). For cervical cancer, 55.0\% of the women had been screened, quite comparable to our finding. This data was collected in the same time period. The present study sample was almost exclusively low income, Korean women with low levels of education. The screening rates of the ethnic specific clinics seem favorable in light of Wismer's sample that contained a more economically heterogeneous Korean sample.

We do not have data to explain the significant difference in screening rates between the Chinese and Korean samples. One possible factor is that due to differing waves of immigration to California, community agencies that serve the Chinese community in California tend to be more established than those in the Korean communities. We do know, however, that with the development of the Federal and State breast and cervical cancer screening programs since 1994, the Korean agencies have been very active in recruiting women for screening and their screening rates are expected to increase accordingly in subsequent years (Maxwell, Bastani, \& Warda, 1998).

The low clinical breast examination rates in the ethnic specific clinics are also of concern. McPhee and colleagues (2002) have reported similar findings. Cultural factors may play a role here. Many of the doctors in the community clinics are of the same ethnicity as the patients. It is possible that ethnic physicians are more respectful of a woman's modesty and therefore do not do the examination. Related, if trained in their home countries, they may be unaware of the increasing risk of Asian American women to breast cancer in the U.S (McPhee et al., 2002). Another explanation might be that clinical examinations services were not recorded in the medical record. Nonetheless, this presents a target area for in-service education programs for the medical and health care staff so that the full screening examinations are done according to current practice guidelines and national objectives.

Overall, our data suggest that even among lowincome Asian American women in California who received health services in a community clinic setting between 1992 and 1994, rates of BSE instruction, CBE, mammography and Pap screening were well below the national public health goals. The rates of screening in these ethnic specific clinics however were on par or exceeded the rates for English speaking Asian American women for BSE, mammography and Pap test. Our conclusion is that ethnic specific clinics are very effective in providing services to these hard-to-reach women.

\section{Limitations}

Several factors limit the validity of our findings. First, since patients were seen in different agencies and clinics, clinical encounters were not recorded in a standardized fashion, and all of the discussions between the clinician and the patient may not have been noted (such as the clinical breast examination or self breast examination education) if they were not pertinent to the presenting problem or chief complaint. Additionally, if mammograms were not conducted in the agency, the clinician may have verbally recommended that the patient obtain a mammogram, but, if no specific referral or follow-up was recorded, the number of actual examinations, teaching sessions, and referrals would be reduced.

Second, health insurance status may be vulnerable to miscoding in the medical record. In this study, patients who reported that they would "self-pay" for the services received at the clinic were coded as "uninsured". A few of the patients choosing to pay for these services had third party coverage. In particular, staff reported that several women used clinic-screening 
services at the ethnic clinic rather than other services offered by their private insurance plans because of the cultural competency of community clinic staff. Similarly, it is possible that patients who have a long standing relationship with a community clinic provider will continue to see that provider even though it requires out of pocket payment. This data, therefore, may overestimate the number of uninsured in the study population. Based on reports from the clinic staff, however, we estimate that this error would be less than $5 \%$.

Third, in interpreting the data, it is important to note that this sample is not generalizable to all low-income women in the three populations. As the sociodemographic data indicate, these women had lived in the U.S. an average of 8.7 years. Moreover, samples were drawn disproportionately from particular clinics where one ethnic group predominated and were not population based. For example, $75 \%$ of the Korean women received their services from one southern California clinic, and all of the Thai women were from one southern California clinic. Although we know the clinics draw clientele from a large geographic area due to the linguistic and cultural capacity of their staff and providers, these populations are likely not representative of their ethnic populations, and only represent those individuals who utilize the services of these clinics.

Last, the variation in rates of screening may also reflect the duration and intensity of clinic outreach into their respective communities. For example, the Chinese clinics have a longstanding presence in their communities, whereas the other participating clinics established outreach programs for more recently arrived populations.

\section{Implications}

Migration studies have indicated that breast cancer rates are at least $60 \%$ higher in Asian American women in the U.S. than in those in their native countries (Falk, 2002; Ziegler et al., 1993). Immigrants with only 10 years of residence in the U.S., have an $80 \%$ greater likelihood of developing breast cancer than new immigrants, and for Asian American women born in the U.S., the risk of breast cancer approaches that of white women in the same geographic areas (Kagawa-Singer et al., 1997; Miller \& Meier, 1998). Notably, for Asian American women born in the U.S. who have at least one grandparent born in the west, breast cancer rates were higher than whites living in the same communities (Falk, 2002; Ziegler et al., 1996). These migration studies indicate that cultural beliefs and practices do affect cancer incidence through their impact on and interaction with prevention practices, diet, lifestyle, and environmental factors. The increasing rate of breast cancer in Asian American women indicate that this disease is affecting a large number of Asian American women now, and will increase significantly as these women age and acculturate to western lifestyles. Prevention and early detection programs are essential in these communities.

Considering the diversity of this population, cost effective and culturally based strategies are needed to reach this diverse population of women. Education efforts must target both ethnic professionals and specific ethnic communities. Finally, more population based Asian American ethnic specific surveys in at least the major languages are needed to accurately represent the breast and cervical cancer screening needs of Asian American women in the separate Asian American subgroups (Ponce, 2003).

The absence of accurate and representative data on the screening practices of Asian American women has both programmatic and policy implications. In the absence of such data, it is difficult, if not impossible, to assess the need for culturally specific programs to promote breast and cervical cancer screening among Asian American women. Moreover, without baseline data on current rates of screening for the Asian American subgroups, it is impossible for programs to assess their impact and modify their efforts accordingly. Screening rates in Asian Americans continue to be well below the national screening guidelines (Chen, 2004). Priority targeted efforts are needed to overcome the structural and cultural barriers to screening and early detection practices in these highly 
diverse and hard-to-reach populations. More data from these Asian American ethnic specific clinics are needed to add to the development of accurate baseline data in order to design more effective and appropriate outreach and inreach programs, and to support sustained research efforts to increase breast and cervical cancer screening practices for Asian American women.

Notably, the apparent culturally acceptable service delivery provided by ethnic specific health clinics seems to be critical and essential in serving this low-income monolingual sector of the Asian American community. To work towards the Healthy People 2010 goal of eliminating health disparities and achieving the recommended screening rates, program planners and funders would be wise to financially support these community based agencies so that these populations can be appropriately screened and treated, and we can avoid unnecessary and avoidable morbidity, mortality, and financial burden in these communities.

\section{References}

American Cancer Society. (2000). Cancer facts and figures 2000. Atlanta: Author.

American Cancer Society. (1996). Cancer facts and figures for minority Americans. Atlanta: Author.

Census, U. B. O. T. (1993b). Money income of household, families, and persons in the United States: 1992 (Government Printing Office). Washington, D.C.: U.S. Bureau of the Census.

Chen, A., Lew, R., Thai, V., et al. (1992). Behavioral risk factor survey of Chinese - California, 1989. Morbidity \& Mortality Weekly Report, 41, 266-270.

Chen, J. D. A., Kagawa-Singer, M., Pourat, N., Wold, C. (2004). Disaggregating Asian and Pacific Islander women to assess cancer screening. American Journal of Preventive Medicine, 27, 1-6.

Falk, F. T., Hoover, R. N., Pike, M. C., Wu, A. H., Monura, A. M., Kolonel, L. N., West, D. W., Ziegler, R. G. (2002). Does place of birth influence endogenous hormone levels in Asian-American women? British Journal of Cancer, 87, 54-60.

Jenkins, C., McPhee, S., Bird, J., \& Bonilla, N. (1990). Cancer risk and prevention practices among Vietnamese refugees. The Western Journal of Medicine, 153, 34-39.

Jenkins, C. N., Le, T., McPhee, S. J., Stewart, S., \& Ha, N. T. (1996). Health care access and preventive care among Vietnamese immigrants: do traditional beliefs and practices pose barriers? Social Science and Medicine, 43(7), 1049-1056.

Kagawa-Singer, M., Hikoyeda, N., \& Tanjasiri, S. P. (1997). Health issues for elderly Asian Pacific Islanders. In K. Markides and M. Miranda (Eds.), Minorities, Aging and Health. Thousand Oaks: Sage.

Kagawa-Singer, M., \& Maxwell, A. (1998). Breast cancer screening in Asian and Pacific Islander American women. In D. Weiner (Ed.), Preventing and Controlling Cancer in the Americas: Canada, United States, and Mexico (pp. 147-166). Los Angeles: Greenwood Publishers.

Kagawa-Singer, M., \& Pourat, N. (2000). Asian American and Pacific Islander breast and cervical carcinoma screening rates and healthy people 2000 objectives. Cancer, 89(3), 696-705.

Kwong, S. (2004). Cancer statistics for California's Asian Americans. Paper presented at the AANCART Community Partnerships in Cancer Control: From Vision to Synergy to Reality, Sacramento, CA.

Lai, E., and Arguelles, D. (2003). The new face of Asian Pacific America: Numbers, diversity, and change in the 21st century: Los Angeles: UCLA Asian American Studies Center Press.

Lee, M., Lee, F., \& Stewart, S. (1996). Pathway to early breast and cervical detection for Chinese American women. Health Education Quarterly, 23(Suppl.), S76-S88.

Lin-Fu, J. S. (1993). Asian and Pacific Islander Americans: An overview of demographic characteristics and health care issues. Asian American and Pacific Islander Journal of Health, 1(1), 20-36.

Lovejoy, N. C., Jenkins, C., Wu, T., Shankland, S., \& Wilson, C. (1989). Developing a breast cancer screening program for Chinese-American women. Oncology Nursing Forum, 16(2), 181-187.

Maxwell, A. E., Bastani, R., \& Warda, U. S. (1998a). Mammography utilization and related attitudes among Korean-American women. Women and Health, 27(3), 89-107. 
Maxwell, A. E., Bastani, R., \& Warda, U. S. (1998b). Misconceptions and mammography use among Filipino- and Korean-American women. Ethn Dis, 8(3), 377-384.

McPhee, S. J., Bird, J. A., Ha, N.-T., Jenkins, C. N. H., Fordham, D., \& Le, B. (1996). Pathways to early cancer detection for Vietnamese women: Suc khoe la vang! (Health is gold!). Health Education Quarterly, 23(Suppl.), S60-S75.

McPhee, S. J., Nguyen, T. T., Shema, S. J., Nguyen, B., Somkin, C., Vo, P. et al. (2002). Validation of recall of breast and cervical cancer screening by women in an ethnically diverse population. Preventive Medicine, 35(5), 463-473.

McPhee, S. J., Stewart. S., Brock, K. C., Bird, J. A., Jenkins, C. N., Pham, G. Q. (1997). Factors associated with breast and cervical cancer screening practices among Vietnamese American women. Cancer Detection and Prevention, 21(6), 510-521.

Menon, M., Teh, C. H., \& Chua, C. L. (1992). Clinical and social problems in young women with breast carcinoma. Australian and New Zealand Journal of Surgery, 62(5), 364-367.

Miller, B. A., Kolonel. L., Berstein, L, Young, J. L., Swanson, G. M., West, D. W., Key, C. R., Liff, J. M., Glover, C. S., Alexander, G. A. (Eds.) (1996). Racial/ethnic patterns of cancer in the United States, 1988-1992. Bethesda, MD: National Cancer Institute.

Miller, F. G., \& Meier, D. E. (1998). Voluntary death: a comparison of terminal dehydration and physician-assisted suicide [Comment]. Annals of Internal Medicine, 128(7), 559-562.

Office of Management and Budget. (1997). Revision to the standards for the classification of federal data on race and ethnicity. Washington DC: Executive Office of the President, Office of Information and Regulatory Affairs.

Parker, S. L., Davis, K. J., Wingo, P. A., Ries, L. A., \& Heath, C. W., Jr. (1998). Cancer statistics by race and ethnicity. CA: A Cancer Journal for Clinicians, 48(1), 31-48.

Pham, C. T., \& McPhee, S. J. (1992). Knowledge, attitudes, and practices of breast and cervical cancer screening among Vietnamese women. Journal of Cancer Education, 7(4), 305-310.

Ponce, N., Babey. S., Etzioni, D. A., Spencer, B. A., Brown, E. R., Chawla, N. (2003). Cancer screening in California: Findings from the 2001 California health interview survey. UCLA Center for Health Policy and Research, 1-74.

Sadler, G. R., Dhanjal, S. K., Shah, N. B., Shah, R. B., Ko, C., Anghel, M., et al. (2001). Asian Indian women: knowledge, attitudes and behaviors toward breast cancer early detection. Public Health Nursing, 18(5), 357-363.

Shinagawa S, Chen M, Kagawa-Singer M, Tsark J, Mackura G, Palofax N. (1999) Reporting of U.S. Cancer rates of Asian Americans and Pacific Islanders. Journal of Registry Management (Special Populations Issue), Kathleen A. Kealey, CTR, Editor. Seattle, WA 98103-1024. 26:4:128-141.

Small, C. A. (1997). Voyages: From a Tongan villages to American suburbs. Cornell University Press.

Tanjasiri, S. P., Wallace, S. P., \& Shibata, K. (1995). Picture imperfect: hidden problems among Asian Pacific islander elderly. Gerontologist, 35(6), 753-760.

Taylor, V., Jackson, J., Schwartz, S., Yutaka Y., Tu, S., Thompson, B. (1998). Cervical cancer control in a Cambodian American population. Asian American and Pacific Islander Journal of Health Proceedings to CCAAPI Cancer Concerns for Asian Americans \& Pacific Islanders, 6(2), 368377.

Taylor, V. M., Hislop, T. G., Jackson, J. C., Tu, S. P., Yasui, Y., Schwartz, S. M., et al. (2002). A randomized controlled trial of interventions to promote cervical cancer screening among Chinese women in North America. Journal of the Natational Cancer Institute, 94(9), 670-677.

U.S. Census Bureau. (2000). Census 2000. Washington, DC: Author.

Wismer, B., Chen, A. M., Kang, S. H., Lew, R., Min, K., Moskowitz, J., et al. (1996). Community participatory research in the Korean community: The health is strength project. Abstract. American Public Health Association, Session 2224.

Wismer, B. A., Moskowitz, J. M., Chen, A. M., Kang, S. H., Novotny, T. E., Min, K., et al. (1998). Mammography and clinical breast examination among Korean American women in two California counties. Preventive Medicine, 27(1), 144-151. 
Ziegler, R. G., Hoover, R. N., Nomura, A. M., West, D. W., Wu, A. H., Pike, M. C., et al. (1996). Relative weight, weight change, height, and breast cancer risk in Asian-American women. Journal of the National Cancer Institute, 88(10), 650-660.

Ziegler, R. G., Hoover, R. N., Pike, M. C., Hildesheim, A., Nomura, A. M., West, D. W., et al. (1993). Migration patterns and breast cancer risk in Asian-American women. Journal of the National Cancer Institute, 85(22), 1819-1827.

\title{
Acknowledgements
}

This study was supported by the American Cancer Society, California Division for Drs. Wong and Shostak, and by a grant from the Oncology Nursing Society and the National Research Center for Asian American Mental Health, UCLA. We also wish to thank Jeff Caballero, MPH and Rod Lew MPH Stephen Jiang, MPH, and Ying-Ying Ming, Ph.D., all formerly of AAPCHO, and the following individuals at each of the AAPCHO agencies for their assistance with the study design and data collection: Karen Lam at Asian Health Services, Christina Hsu at Chinatown Service Center, Lori Min formerly at Koryo Health Center, Dr. Daniel Chan at Northeast Medical Center, and Grace Sison at THE Clinic. Special thanks are extended to Ms. Deborah Riopelle, MPH for her assistance with data analysis, and Ms. Sandra Ho for preparation of the manuscript.

\author{
Author Information \\ Marjorie Kagawa-Singer, Ph.D., R.N., M.N.* \\ Associate Professor \\ UCLA School of Public Health \\ Box 951772 \\ Los Angeles, CA 90095-1772 \\ Ph. 310-825-9481 \\ Fax. 310-794-1805 \\ E-Mail: mkagawa@ucla.edu \\ Liane Wong, Dr.P.H., M.P.H., Director \\ Institute for Health Policy Solutions \\ San Mateo, California \\ Sara Shostak, Ph.D., M.P.H. \\ Robert Wood Johnson Health and Society Scholar \\ Columbia University, New York \\ Chantal Raymer Walsh, M.S.P.T., Physical Therapist \\ Alta Bates Summit Medical Center \\ Oakland, CA \\ Rod Lew, M.P.H., Director \\ Asian Pacific Partners for Empowerment and Leadership (APPEAL) \\ 439-23rd Street \\ Oakland, CA 94610 \\ * corresponding author
}

